Int. J. Electrochem. Sci., 15 (2020) $6330-6342$

\title{
Improving Interfacial Problems between the Cathode and Solid- State Electrolyte by Coating ETPTA-PEG onto the Surface of $\mathrm{LiNi}_{0.8} \mathrm{Co}_{0.1} \mathrm{Mn}_{0.1} \mathrm{O}_{2}$
}

\author{
Hongzhi Wang ${ }^{1}$, Yi Bo Shang ${ }^{1}$, Weiguo Zhang ${ }^{1}$, Fei Ding ${ }^{2, *}$, Lin Sang ${ }^{2,3}$ \\ ${ }^{1}$ Department of Applied Chemistry, School of Chemical Engineering and Technology, Tianjin \\ University, Tianjin 300350, PR China \\ ${ }^{2}$ Tianjin Cetc New Energy Research Institute Co., Ltd \\ ${ }^{3}$ National Key Laboratory of Science and Technology on Power Sources, Tianjin \\ *E-mail: hilldingfei@163.com
}

doi: $10.20964 / 2020.07 .20$

Received: 3 February 2020 / Accepted: 9 April 2020 / Published: 10 June 2020

\begin{abstract}
In recent years, the rapid development of the electric vehicle industry has led to the requirement of Liion batteries (LIBs) with a higher energy density and better safety. Therefore, solid-state lithium batteries with the above advantages have attracted a lot of attention. However, solving the interfacial problem between cathodes and the solid-state electrolyte has become a major challenge in the practical application of solid-state lithium-ion batteries. In this article, ETPTA (trimethylolpropane ethoxylate triacrylate)-PEG (poly(ethylene glycol)) is introduced onto the surface of $\mathrm{LiNi}{ }_{0.8} \mathrm{Co}_{0.1} \mathrm{Mn}_{0.1} \mathrm{O}_{2}$ cathode materials by ultraviolet irradiation. TEM and FTIR analyses reflect the existence of the composite coating layer. Electrochemical tests reveal that the coated material has better cycle stability (capacity retention remains $84 \%$ after 100 cycles), lower interfacial impedance and higher rate capabilities (34 $\mathrm{mA} \mathrm{h} \mathrm{g}^{-1}$ at $2 \mathrm{C}$ ). These results reflect the fact that the coating layer plays a significant role in improving the interfacial contact between the cathode and solid-state electrolyte and suppressing surface side reactions.
\end{abstract}

Keywords: Ni-rich cathode materials, interfacial problem, surface modification

\section{$\underline{\text { FULL TEXT }}$}

(C) 2020 The Authors. Published by ESG (www.electrochemsci.org). This article is an open access article distributed under the terms and conditions of the Creative Commons Attribution license (http://creativecommons.org/licenses/by/4.0/). 